\title{
Wage- and profit-led regimes under modern finance: an exploration*
}

\author{
Amit Bhaduri \\ Jawaharlal Nehru University, New Delhi, India \\ Srinivas Raghavendra** \\ National University of Ireland, Galway, Ireland
}

This paper generalizes the principle of effective demand to incorporate banking and finance as two distinct sectors. The traditional commercial banking sector is regulated and the modern shadow banking sector is mostly an unregulated provider of financial services. Through a stylized model the interconnectedness between the two sectors is analysed. The analysis shows how an almost infinite supply-side capacity of finance is created and explores its relation to the level of aggregate demand in the real economy. The impact of finance on the real economy is explored in both profit-and wage-led regimes at different levels of interconnectedness between commercial and investment banking.

Keywords: profit realization, securitization, commercial banking, investment banking, profit-led, wage-led, effective demand, financialization

JEL codes: $E 10, E 12, E 40, E 44, E 51$

\section{INTRODUCTION}

This paper has two interrelated objectives. First, it presents a general formulation of the principle of effective demand, integrating Keynes's theory of investment saving equilibrium for commodity market clearance with Kalecki's theory of profit determination. The general framework accommodates many sectors, including banking and a modern financial sector, to derive an extended equilibrium condition (Section 2). This in turn links changes in effective demand with the changes in the asset liability structure of the economy in a stock-flow consistent framework (Section 3). Second, with the aid of the extended equilibrium condition involving banking and modern finance, we examine how income and profit determination are influenced by the presence and expansion of a modern financial sector through various credit instruments like securities, derivatives, swaps, etc. in different situations characterized by the degree of interconnectedness between banking and finance. We study in particular two situations, based either on no integration between commercial and investment banking (Section 4), or a contrasting situation of a greater degree of integration between the two (Section 5). Scenarios characterized by different degrees of interconnectedness between commercial and investment

* We gratefully acknowledge valuable comments from Heinz Kurz, Rune Skarstein, Jerzy Osiatyński, Frank Conaty, Marco Missaglia and the late Kazimierz Laski at various stages of the paper's writing. All the remaining errors are ours.

** Corresponding author: email: s.raghav@nuigalway.ie. 
banking are shown to affect the characteristics of the path of demand-determined output, influencing in particular the emergence of wage-led and profit-led regimes, and the possibility of transition between them (Sections 4 and 5). The paper concludes with some observations about possible extensions and policy relevance of the analysis (Section 6).

\section{THE PRINCIPLE OF EFFECTIVE DEMAND}

Consider an economy without foreign trade, capital flows, and government. It consists of two vertically integrated sectors, each producing all the necessary intermediate inputs for its final output - a good for current consumption and a good not meant for immediate consumption, and needed as means of production for augmenting future production capacity. ${ }^{1}$ Although these logical categories are necessarily fuzzy in real life, this basic two-sector model due to Marx (1885) helps to distinguish production for current use from production for future use and their implications for aggregate demand. Placed in the Keynesian short-period context, capital goods are non-malleable and are specific to the use of a sector within that period.

While consumption and investment goods are distinct and non-convertible in physical terms, all relevant variables are measured in 'money,' in a limited sense. This serves as the unit of account but is devoid of the function of store of either macroeconomically converting one good into another in the market (without international trade) in the short period, or serving as a store of value. ${ }^{2}$

The employed workers $(L)$ are divided between the consumption $\left(L_{c}\right)$ and investment $\left(L_{i}\right)$ goods sector at a uniform wage rate $(w)$ with all wages consumed for simplicity. Macroeconomic balance requires that the surplus of the consumption sector over the wage bill of that sector is either consumed by workers in the investment sector and/or by the capitalists out of their profit; that is:

$$
\left(X_{c}-W_{c}\right)=W_{i}+C_{c},
$$

where $W_{i}=w L_{i}$ the wage bill of the investment sector and $C_{c}=$ the capitalist's consumption out of profit.

Equation (1) is central to the theory of effective demand as it shows how surplus or potential profit is generated on the left-hand side as excess over wage bill, and is realized as money profit on the right-hand side through sale in the market. In this case, the market size is determined by the two components of effective demand, the demand for consumption goods created by the wage bill of the non-consumption goods (investment) sector $\left(W_{i}\right)$ plus consumption out of profit by the capitalists in both sectors $\left(C_{c}\right)$.

If equality does not hold in (1), expectations about the volume of sales by the capitalists would be unfulfilled, that is, the left-hand side of (1) would be greater than the right-hand side, and the surplus would remain unsold as unplanned inventory accumulation. If it falls short of the right-hand side, inventories would have to be run down in an unplanned manner. Both situations become unsustainable over time.

The theory of effective demand emphasizes that surplus $\left(X_{c}-W_{c}\right)$ rather than total production $\left(X_{c}\right)$ has to find a market in addition to the market created within the sector

1. See Pasinetti $(1974 a$; 1981) for an analytical treatment on the inter-industrial vertically integrated analysis.

2. The liquidity as well as the store-of-value aspect of money and other financial assets will be introduced later when the banking and finance sectors are explicitly introduced. 
by consumption of workers employed in the consumption sector $\left(W_{c}\right)$. A fundamental insight of the principle of effective demand linking surplus, and not total production, to a market beyond the consumption sector, for profit realization gives rise to the multiplier mechanism. For any given increase in demand or market size, output has to increase several times until the surplus generated as a fraction of the total output matches the size of the additional market. Interestingly, it also warns against a blind drive for efficiency without consideration of demand, fostered as a habit of thought in conventional economic thinking. Higher labor productivity $\left(X_{c} / L_{c}\right)$ as a measure of efficiency at an unchanged wage rate only exacerbates the problem of deficient demand at the macroeconomic level, even though it might be microeconomically more profitable for some individual firms. This is similar to the argument that cutting (real) wage can help some but not all firms.

When the surplus of the consumption sector finds an adequate market outside that sector, physical surplus gets realized as money profit $\left(R_{c}\right)$. Equation (2) shows this explicitly as

$$
\left(X_{c}-W_{c}\right)=W_{i}+C_{c}=R_{c}
$$

By adding the realized profit of the investment sector $\left(R_{i}\right)$ on both sides of the last part of equation (2) and subtracting $C_{c}$ from both sides, we obtain

$$
\left(W_{i}+R_{i}\right)=I=\left(R_{c}+R_{i}\right)-C_{c}=R-C_{c}=S=s R,
$$

where $R=\left(R_{c}+R_{i}\right)$ is the total realized profit, and $s$ is the (average and marginal) propensity of the capitalists to save from profits $(1>s>0)$.

Equation (3) is the profit realization equation formulated by Kalecki (1933 [1971]; $1937 ; 1942$ [1971]), and also the investment saving equality equation due to Keynes (1936). Investment $(I)$ as value added by that sector on the left-hand side equals capitalists' profit income, $R$, minus their consumption $C_{c}$, that is, their savings, which is also the total savings of the economy $(S)$, since workers do not save by assumption. ${ }^{3}$

In deriving equation (3) from (2), profit realization of the investment sector $\left(R_{i}\right)$ is assumed without explanation. This raises a problem of compatibility of time scales between short period analysis and the production period for capital goods, the latter being longer than the short period in the definitions used by Marshall and Keynes. Consequently, paying back loans from profit earned from completed capital goods takes us beyond the short period. A way to get around the problem is to note that in (3) $I$ represents total investment expenditure which is the value added, that is, profit $\left(R_{i}\right)$ plus wage $\left(W_{i}\right)$ in that sector. Assuming all sectors purchase investment goods at prices that cover profit as well as wage costs of firms making those investment goods, the time scale compatibility problem of profit realization in the investment sector can be bypassed.

To incorporate the financing of investment (also consumption) expenditure in the above framework, we introduce two separate sectors for banking and finance respectively: the financial 'core,' and the financial 'periphery.' The financial 'core' (the central bank and the commercial banks with the central bank acting as the lender of last resort) is

3. Without affecting the main argument, this assumption can be relaxed in various alternative ways, for example a positive saving propensity for workers, a uniform saving propensity for all classes, saving propensity of firms determining retained profit and wage plus distributed profit as mixed income of households with a uniform saving propensity (Pasinetti 1974b). 
surrounded by the financial 'periphery' (that is, hedge funds, investment banks, etc.) that is neither supervised closely by the central bank nor enjoys the 'lender of last resort' guarantee from the central bank. Therefore, in a modern economy with an advanced financial sector, there is a distinction between 'money' (cash plus demand deposits or 'high-powered' money) as credit provided by the financial core, and 'money' in the form of various credit instruments that circulates through the financial periphery. For simplicity of notation, we represent the value added by the central bank and the supervised commercial banks in the financial core by $B$, while the remaining financial periphery's value added is denoted by $F$.

Continuing with the same assumption that all wages are consumed with saving coming only from profit, the market for the surplus of the consumption sector is provided by wage earners in the investment $(I)$, banking $(B)$ and finance $(F)$ sectors plus consumption by capitalists in all sectors $\left(C_{c}\right)$ in this fourfold classification of sectors. This yields an extended version of equation (2) as

$$
W_{i}+W_{b}+W_{f}+C_{c}=R_{c}
$$

where the relevant subscript indicates the corresponding sector.

Adding the realized profit $\left(R_{i}+R_{b}+R_{f}\right)$ and subtracting $C_{c}$ from both sides of equation (4), we obtain the corresponding extended version of equation (3) as

$$
I+B+F=\left(R_{c}+R_{i}+R_{b}+R_{f}\right)-C_{c}=R-C_{c}=S .
$$

Equation (5) is merely a restatement of the saving-investment equality condition involving explicitly the banking and the financial sectors. If the value added of the banking sector $(B)$ is assumed to be only total net interest income on loans advanced by it, ${ }^{4}$ we can deduct the net interest income accruing to banks from both sides of (5) and rewrite:

$$
I+F=S,
$$

where saving $S$ represents saving out of profit without interest income by banks.

\section{INTERACTION BETWEEN THE REAL AND THE FINANCIAL SECTOR}

Interpretation of equations (5) and (6) through a stock-flow consistent accounting framework provides a way of analysing disequilibrium between expenditure and income in the real economy. It resembles some aspects of how investment saving equality is brought about by adjustments in current and capital accounts in the case of an open economy. In analysing these linkages we examine the asset/liability structure of the economy using a stock-flow matrix. The sectoral structure is simplified by clubbing together the consumption $(C)$ sector and the investment $(I)$ sector as the real commodity producing sector $(R)$. The interactions between these sectors, the real sector $(R)$, the banking sector $(B)$ and the financial periphery $(F)$, are then examined through their respective assets/liability positions. This yields a $3 \times 3$ square matrix where $L_{i j}$ denotes

4. This restricts commercial banks to only taking deposits and earning interest income in a fractional reserve system. In general, the commercial banks also take part in trading their assets for capital gain. We discuss this scenario in section 5 . 
the stock liability of sector $i$ to $j$, and $l_{i j}$ the corresponding flow or change in liability of sector $i$ to $j$, with $i, j=(b, f, r)$ in obvious notations used in subscripts. Since money is defined as cash plus demand deposits, that is, the liability of the banking sector, $L_{b r}$ and $L_{b f}$ denote the cash holdings of the real and financial periphery respectively. Since financial securities are the liabilities of the financial periphery, $L_{f r}$ and $L_{f b}$ denote the holdings of financial securities by the real sector and the financial core respectively. Also, since each entry simultaneously denotes the liability of the row sector and the asset of the column sector, an increase in liability of sector $i$ vis-à-vis $j$, which is denoted by $\left(+l_{i j}\right)$, is caused by excess expenditure over income and the corresponding decrease in assets $\left(-a_{i j}\right)$, while a decrease in liability $\left(-l_{i j}\right)$, and the corresponding increase in assets $\left(+a_{i j}\right)$, is caused by an excess of income over expenditure.

Starting from a flow equilibrium depicted by equation (5) as well as stock equilibrium in assets and liabilities shown by capital letters in Table 1, consider the case where the increase in investment expenditure in the real sector is financed by issuing new equities by firms in the real sector. In this case, assuming that they are held only by the financial periphery, the liability of the real sector vis-à-vis the financial periphery increases $\left(+l_{r f}\right)$, as shown by the bracketed term for the corresponding entry in Table 1, which simultaneously increases the asset position of the financial periphery vis-à-vis the real sector.

While the financial core's position remains the same $(\Delta B=0)$, the balance (5) is achieved by a corresponding increase in the liability position of the financial periphery vis-à-vis the real sector through issuing new securities using the equities of the latter as the underlying assets. This is shown by the bracketed term $\left(+l_{f r} \equiv-a_{f r}\right)$ in Table 1 . Thus, in this case the equilibrium adjustment yields

$$
\Delta(I-S)=\left(+l_{r f}\right)=-\Delta B-\Delta F=-a_{f r}=\left(+l_{f r}\right) .
$$

In a more general case, where both the loans advanced by the banking sector $\left(+l_{r b}\right)$ and the equities $\left(+l_{r f}\right)$ issued by the real sector are used as the underlying assets for securities issued by the financial periphery, the flow equilibrium is achieved through (8) as shown in Table 2 with change in liabilities during a period shown in brackets (as in Table 1).

In terms of the excess expenditure of the real sector met by increased liability to the banking sector through borrowed loans $\left(+l_{r b}\right)$, the first term on the left-hand side of $(8)$ means a corresponding increase in the asset position of the banking sector vis-à-vis the real sector $\left(+a_{b r}\right)$, which is equivalent to a corresponding decrease in the liabilities of the banking sector $\left(-l_{b r}\right)$. In addition, excess expenditure met by increased liability of

\section{Table 1 Equities financed investment expenditure}

\begin{tabular}{lccc}
\hline Liabilities & $B$ & $F$ & $R$ \\
\hline$B$ & & & \\
\hline$R$ & 0 & $L_{b f}$ & $L_{b r}$ \\
\hline & - & 0 & $L_{f r}\left(+l_{f r} \equiv-a_{f r}\right)$ \\
\hline
\end{tabular}


Table 2 Loan and equity financed investment expenditure

\begin{tabular}{lccc}
\hline Liabilities & $B$ & $F$ & $R$ \\
\hline$B$ & & & \\
\hline$R$ & 0 & $L_{b f}\left(+l_{b f}\right)$ & $L_{b r}$ \\
\hline & - & 0 & $L_{f r}\left(+l_{f r}\right)$ \\
\hline
\end{tabular}

the real sector through the issuance of new equities, which are held by the financial periphery $\left(+l_{r f}\right)$, as shown by the second term on the left-hand side of $(8)$, represents a corresponding increase in the asset position of the financial periphery vis-à-vis the real sector $\left(+a_{f r}\right)$. In this case, the equilibrium adjustment in $(5)$ arising from the increased liability of the real sector due to excess expenditure yields

$$
\Delta(I-S)=\left(+l_{r b}\right)+\left(+l_{r f}\right)=-\Delta B-\Delta F=-a_{b f}-a_{f r}=\left(+l_{b f}\right)+\left(+l_{f r}\right),
$$

where $+l_{r b} \equiv-a_{r b} \equiv+a_{b r} \equiv-l_{b r}$. Since in this case the banking sector sells part of its loan book to the financial periphery, the corresponding increase in the cash flow for the financial periphery vis-à-vis the banking sector is $+l_{b f}$ (equivalent to $-l_{b r}$ ). This allows the financial periphery to use this cash flow as an underlying asset to issue new financial securities. The consequent reduction of the banking sectors' assets vis-à-vis the financial periphery is $-a_{b f}$ (equivalent to $+l_{b f}$ ), which is denoted by the $-\Delta B$ term on the right-hand side of $(8)$. The second term $\left(+l_{f r}\right)$ on the righthand side of (8) denotes the increase in liabilities issued by the financial periphery using the equities of the real sector as the underlying asset, which is equivalent to a reduction of its assets vis-à-vis the real sector $-a_{f r}$. This is denoted by the $-\Delta F$ term on the right-hand side of (8). Thus, in this case, where both the loans of the banking sector to the real sector and equities of the real sector are used as underlying assets for the financial securities, the expansion base of the financial periphery is greater by $+l_{b f}$ than in the previous case (7), equivalent to the loans advanced by the banking sector to the real sector to meet its excess expenditure.

Investment (also consumption) expenditure by the real sector can be financed by retained profit, bank loans, and its own equities (that is, the promise to pay from future streams of income). While these are distinct sources of finance, modern financial techniques of securitization allow for combining them in different proportions to be rated and insured privately, and issue new future flows of income earning securities. The financial periphery may also use these securities as underlying assets to build a pyramid of new income bearing financial instruments. The impact of these relatively recent developments of modern finance on demand-determined paths of expansion, particularly in relation to profit- and wage-led regimes, are analysed in the specific cases outlined in (7) and (8) in the following Sections 4 and 5 respectively. First, we consider the case in which the financial periphery builds new pyramids of credit instruments based only on equities purchased from firms in the real sector (Section 4 corresponding to the case shown in equation (7)), and next the more complex case where it takes over a part of the loan book of banks (which may also include bank loans to households as 
well as to firms for industrial projects) along with equities purchased from real sector firms (Section 5 corresponding to equation 8 ). ${ }^{5}$

\section{INTERACTION BETWEEN THE REAL AND THE FINANCIAL SECTOR WITH PASSIVE BANKING}

The case to be considered in this section is based on the assumption used in simplifying equation (6) from (5). In its most traditional form, commercial banking is meant to advance loans to the real sector for financing part of their consumption and investment expenditures. The net interest income of the commercial banking sector is its value added, which is divided between wages and profit of that sector.

The financial periphery exists as a separate entity, but to maintain a strict separation between commercial banking and the financial periphery we assume they purchase no papers, loan books, or bonds of the banking sector. ${ }^{6}$ The financial periphery can make profit through a process of securitization of equities issued by firms, and loans advanced by banks. In this section, we analyse the simpler case corresponding to equation (7) where only equities of real sector firms serve as the underlying asset for securities issued by the financial periphery. Note this simplification would not be valid, for example, if commercial banks and investment banks have interconnected activities corresponding to the scenario described in Table 2 and equation (8), which is the subject matter of Section 5 .

Let $k$ be the fraction of equities that are held by the financial periphery being used in creating securities (see Table 2). We model this as a process of successive slicing and repackaging of the underlying assets resulting in different weighted averages that are formed in each round. At the initial round, the finance periphery buys equities issued by real sector firms for investment expenditure; that is,

$$
F(0)=k I, 1>k>0,
$$

where $k$ is the fraction of equity-financed investment expenditure of the real sector purchased by the financial periphery.

In the next round, the financial periphery uses these equities as collateral in various combinations to create financial securities offered in the market (for example, collateralized debt obligations (CDOs)) of various descriptions, graded and ordered in 'superior' to 'inferior' tranches depending on their perceived risk as rated by private credit rating agencies. This is meant to give more credence to the quality of these securities, because the typical buyer in the market might have little knowledge about either the quality of various debts that serve as underlying assets, and also of the way in

5. Including cases where the financial periphery is an off-balance-sheet entity or a special purpose entity (SPE) of the commercial banks.

6. The Glass-Steagall Act, passed in 1933 in the US, had two primary objectives: to stop the run on banks and restore public confidence in the US banking system; and to sever the linkages between commercial and investment banking that were believed to have been responsible for the 1929 market crash. However, the Financial Services Modernization Act of 1999 repealed the Glass-Steagall Act, removing barriers for combining the operations of banking companies, securities companies, and insurance companies. The result was various combinations of the same company operating as an investment bank, a commercial bank, and an insurance company. 
which the various debt obligations are combined. The first round of securitization of loans by the financial periphery is shown as

$$
F(1)=a(k I), a>1 \text {. }
$$

In (10), the parameter $a$ can be thought of as a leverage factor, because the newly formed financial securities must exceed the base value of acquired assets (underlying) to generate the possibility of making profit from the sale of these securities.

Although these securities are graded by the rating agencies mostly to improve their marketability, the risk associated with these securities may be reduced further using the device of mutual private insurance, particularly to get protection from potential defaults. This creates a further round of securities or the credit derivatives between two private parties according to which typically one private party pays (insured) a regular premium to the other (insurer) who promises to pay up the whole amount in case of default of some underlying assets of these securities. The derivative trade can also extend to involving several parties in a more complex network. Assuming the volume of derivative trade bears a proportional relation with first round securities created, we obtain

$$
F(2)=b(F(1))=b(a k I), b>1,
$$

where $b>1$ for positive profitability of the derivative trade.

The process can continue with further layers of financial 'innovations' or arrangements creating for example higher order derivatives among unregulated financial firms by mutual agreements in other ways, like swaps between entities, artificial or synthetic swaps within the same entity, etc.

The summation of all the rounds (9), (10), (11), etc. yields the flow of total supply of its output of various credit instruments created during the period by the financial sector as

$$
F^{s}=[F(0)+F(1)+F(2)+\cdots]=[1+a+b a+\cdots] k I .
$$

For the sake of notational simplicity and brevity of exposition, we assume that the increase in value added is uniform along the value chain of financial supply, that is, $a=b=c=(1+x), x>0$. On summation, it yields

$$
F^{s}=\left[\frac{\left.(1+x)^{n}-1\right]}{x}\right] k I,
$$

which represents the flow of total value added by the financial periphery during the period from the supply side.

While this process of value addition by the financial periphery can continue indefinitely over many rounds, and in this sense the potential supply of finance is infinitely elastic, its actual supply is limited during any period. The limit to the supply is set by the demand for these financial products of the finance periphery; that is,

$$
F^{s}=F^{d}=F \text {. }
$$

Since equation (6) implies strict separation between commercial and investment banking, we insert (12) and (13) into (6) and obtain, on simplification:

$$
(1+k Q) I(h, z)=\operatorname{sh} z, \quad Q=\left[\frac{\left[(1+x)^{n}-1\right]}{x}\right] .
$$


We use the same notations and normalization used in Bhaduri and Marglin (1990), in which the arguments of the investment and saving function are: $h=$ share of profit, $z=$ degree of capacity utilization with $z$ being a positive fraction $(1>z>0)$ because normalization sets full capacity or the potential output at unity, and $s=$ the propensity to save out of profit.

Total differentiation and rearrangement of terms in (14) yields

$$
d z / d h=\left[\left(H I_{h}-s z\right)\right] /\left[\left(s h-H I_{z}\right)\right],
$$

where $H=(1+k Q)$.

Two interesting consequences follow from (15) in this case with commercial banking separated completely from investment banking in the financial periphery (see footnote 6). First, the denominator on the right-hand side of (15), which shows the revised stability condition of the Keynesian income generation process through the multiplier, becomes unstable for sufficiently large values of $x$ and $n$ because $H$ is an increasing positive function of both $x$ and $n$. In other words, a sufficiently large financial periphery tends to destabilize the economy. Second, a profit-led regime is more likely to emerge in the stable case as the financial periphery gets larger to augment the first term of the denominator so long as the following inequality condition,

$$
\left(s h / I_{z}\right)>H>\left(s z / I_{h}\right),
$$

is satisfied in a non-empty interval.

\section{INTERACTION BETWEEN THE REAL AND THE FINANCIAL SECTOR WITH ACTIVE BANKING}

The mode of operation of the banking sector $(B)$ is determined to a large extent by the nature of interconnectedness between the banking sector and the financial periphery. This is an important distinguishing aspect of modern financialization characterized by active profit-seeking banking compared to the relatively traditional and accommodative, passive deposit banking which corresponds to an extent in the difference between equation (5) and (6). The financial periphery $(F)$ uses securitization which creates an avenue for the commercial banks to offload problematic assets from their loan book. The financial products generated by securitization of various types of loan that are mixed up in intractable slices, sometimes of real tangible assets as asset-backed securities (ABSs), or backed by debt repayment obligations serving as underlying assets for CDOs with further leveraging yielding CDO-squared, etc. ${ }^{7}$ They usually promise higher income flows to their owners but neither the underlying assets nor their maturity periods are easily tractable to outsiders. It is doubtful if any value is added in the process, and their contribution, if any, is to

7. The modern financial sector has seen, at least since the 1990s, an explosion of 'special purpose entities' (SPEs) or 'structured investment vehicles,' whose securities and derivatives are backed by the underlying tangible or intangible assets like future cash flows on credit card receivables, consumer loans, and mortgages on housing issued by the commercial banks. (See Bhaduri et al. 2015 for a discussion on the process of securitization; and Cordell et al. 2012 for an analysis of the CDO market.). 
alter the time pattern of income flows from the mixed bag of loans in a manner attractive to the buyer.

As already mentioned, the modern finance sector uses both equities of the real sector firms promising dividends and possible capital gains as well as part of the loan book of commercial banks to create these securities. They are then privately rated, insured through devices like derivatives and swaps for their marketability creating a pyramid of loans in the manner stylized in Section 4. The proactive commercialcum-investment banking with private insuring capacity is encapsulated by extending equation (12) as

$$
F^{s}=Q(k I+j B), Q=\left[\frac{\left[(1+x)^{n}-1\right]}{x}\right],
$$

where the fractions $k$ and $j$ are the proportions of equities of firms and loan book of commercial banks acquired by the financial periphery to serve as underlying assets. In particular, the parameter $j$ stylizes interconnectedness between the commercial banks and the financial periphery through investment banks and private insurances.

Eliminating $B$ from (5) with the aid of (13) and (17), we obtain

$$
U I+V F=s h z
$$

where $U=[1-(k / j)]$ and $V=[1+(1 / j Q)]$.

Given other parameters, $U$ is an increasing and $V$ is a decreasing function of $j$, the crucial parameter representing the degree of interconnectedness between the commercial and the investment banking plus private insurance sector.

The implication of this analysis for profit- and wage-led regimes is examined by assuming both $I$ and $F$ are influenced by the same two arguments $h$ and $z$ positively (as in Section 4, equation (14)). Total differentiation of (18) and simplification yields

$$
(d h / d z)=\left(U I_{h}+V F_{h}-s z\right) /\left(s h-U I_{z}-V F_{z}\right) .
$$

It has been shown in Section 2 that the Keynesian multiplier-based income generation is analytically equivalent to the Kaleckian profit realization equation irrespective of the number of sectors considered. Consequently, the same stability condition for income generation would require the denominator of (19) to be positive. In the stable case, the emergence of profit- or wage-led growth depends on whether the numerator of (19) has a positive or negative sign. Since $U$ increases but $V$ decreases at a higher value of $j$, the outcome is ambiguous. However, it suggests the possibility of a switch of regime as the value of $j$ is varied because, with other things remaining the same, the numerator of (19), denoted by $N$, increases with $j$; that is,

$$
\partial N / \partial j>0 \text { if } k Q>F_{h} / I_{h} .
$$

Since $Q$, representing the size of the financial periphery, increases with $x$ and $n$, the likelihood of the inequality being satisfied increases with a larger and more sophisticated financial periphery which increases in turn the possibility of the emergence of a profit-led regime. This suggests that greater interconnectedness between commercial and investment banking captured by a higher value of the parameter $j$ might be more favorable to the emergence of a profit-led regime. 


\section{CONCLUDING OBSERVATIONS}

This paper focused on one of the most important structural aspects of financialization in recent years, which involves increasing interconnectedness between traditional commercial banking and a rapidly expanding modern financial services sector of investment banking including private insurance devices. The connection is most clearly visible in the partial merger of commercial and investment banking. From a legal point of view, commercial banking is under the supervision of a central bank or monetary authority which also acts as its lender of last resort. Beyond this lies the fuzzy zone of a rapidly growing financial sector, which neither enjoys the legal guarantee of lender of last resort from the central bank, nor is it that closely supervised. While creating and guaranteeing its securities, at least in theory it is largely left to its own devices to self-regulate in self-interest, accountable only to the market. In practice however, as regulated commercial banking and unregulated investment banking (and allied activities) increasingly merge, the distinction simply begins to disappear, because the central bank is forced to act as a lender of last resort in times of serious stress to rescue the interlocked financial system. The significance of the questions raised by this paper follows from this particular feature of financialization. It sets up a simple tractable model to explore what happens to aggregate demand in the profitand wage-led regimes under financialization that permits considerable intermingling of commercial and investment banking with private insurance devices to reduce perceived risks of financial products.

For this purpose, we generalize to many sectors Kalecki's profit equation or, equivalently, the Keynesian investment saving equilibrium condition for income determination. Commercial banking and modern finance are incorporated as distinct sectors of the economy in the profit or income determination equation (Section 2). The simplifying assumption that all wages are consumed has been retained throughout, but it can be dropped easily to allow for saving by workers. In particular, without essentially affecting the argument, exceptionally high salaries and bonuses paid especially in the finance sector can be incorporated by assuming that part of the consumption-related expenditure is a constant term unrelated to the level of profit. This would replace, for instance in equations (2) to (5), $C_{c}=(1-s) R+A$, where $A$ is some arbitrary constant. ${ }^{8}$

It is also possible to introduce with minor complications the assumption that part of the salary plus bonus and profit are spent on 'luxury' consumption, while wages of workers are spent entirely on basic consumption goods. ${ }^{9}$ However, a more serious problem arises from borrowing by the wage-earning households from commercial banks for durable consumption like residential housing. This can be treated as a part of the constant in the consumption function of workers with implications for changes in assets and liabilities of sectors (Section 3).

Close interconnectedness between commercial and investment banking permits the transfer of the loan books of regulated commercial banks to the less regulated investment banks in the financial periphery. As a result, 'easy money' becomes an almost intrinsic feature of the interconnected monetary system. By transferring or selling part of their loan book to the financial periphery, the commercial banks create an avenue (for example, special purpose entities) to improve their balance sheets, by offloading

8. The constant term would vanish when total differentials, that is, increments, are considered in the analysis.

9. See Kalecki's essay on 'Class struggle and the distribution of national income,' in Kalecki (1971). 
non-performing 'bad' loans and enhancing their lending capacities. Indeed, they can increase the volume of lending without sufficient caution in seeking higher profit, while the financial periphery can securitize in an opaque manner those loans that are transferred from the loan book of commercial banks. It is a win-win situation for both at least in the short run, while the amalgam of interests between commercial and investment banking becomes an explosive mixture for undermining self-regulating banking behavior. The paper tries to explore how aggregate demand characterized by profit- and wage-led regimes gets affected in the process (Sections 4 and 5). However, in some important respects our explorations remain limited. For instance, the formalism of the explorations hints at the possibility of change of regime from profit- to wage-led growth due to structural features related to interconnectedness of commercial, investment banking, and financial insurance. Nevertheless, it falls short of finding an analytical way of examining whether this might lead to regime change or endogenous oscillatory behavior of regimes.

Perhaps the more important problem, indeed a classical one in Marxist literature, that remains unanswered is the relation between profit in production in the real sector, and profit due to financial trading operations. A significant body of thought claims that the profit accruing to the financial sector is simply a transfer from profit in production in the real sector (Hilferding 1910 [1973]; Foster 2008). We approached the problem within the Kalecki-Keynes framework. Like investment or any other non-consumption goods sector, banking and finance also adds to aggregate demand and therefore helps in realization of profit (Section 2). However, the question of its generation would require deeper analysis of the nature of surplus. Higher profit in commodity production arises from higher level of production in the corresponding sector, driven by higher level of effective demand at constant profit margin, while profit in financial trading mostly results from a greater margin and from financial 'innovation' through the process of securitization (captured by parameters $x$ and $n$ respectively). We are unable to present a deeper analysis in this paper. However, there is a hint that the supply-side expansion of the financial periphery through layers of debt, stylized in this paper, might create a different source of profit margin for the financial periphery through higher values of parameters $x$ and $n$ provided a market exists to absorb these securities. The interconnections between the profit margins of the real and the finance sector may lead to complementary or competitive relationships among these sectors that may even change over time to cause fluctuations between regimes (see condition (20), and the closing discussion in Section 5). These remain mere speculations, and a challenge to future research.

\section{REFERENCES}

Bhaduri, A. and S. Marglin (1990), 'Unemployment and the real wage: the economic basis for contesting political ideologies,' Cambridge Journal of Economics, 14(4), 375-393.

Bhaduri, A., S. Raghavendra, and V. Guttal (2015), 'On the systemic fragility of finance-led growth,' Metroeconomica, 66(1), 158-186.

Cordell, L., Y. Huang, and M. Williams (2012), 'Collateral damage: sizing and assessing the subprime CDO crisis,' Working paper 11-30/R, Federal Reserve Bank of Philadelphia.

Foster, B.J. (2008), 'The financialization of capital and the crisis,' Monthly Review, 59(11), 1-19.

Hilferding, R. (1910 [1973]), T. Bottomore (ed.), Finance Capital: A Study of the Latest Phase of Capitalist Development, London: Routledge \& Kegan Paul.

Kalecki, M. (1933 [1971]), 'Outline of a general theory,' in M. Kalecki, Selected Essays on the Dynamics of the Capitalist Economy (1933-1970), Cambridge, UK: Cambridge University Press, pp. 1-15. 
438 Review of Keynesian Economics, Vol. 5 No. 3

Kalecki, M. (1937), 'The principle of increasing risk,' Economica, 4(16), 440-447.

Kalecki, M. (1942 [1971]), 'The determinants of profits,' in M. Kalecki, Selected Essays on the Dynamics of the Capitalist Economy (1933-1970), Cambridge, UK: Cambridge University Press, pp. 78-92.

Kalecki, M. (1971), Selected Essays on the Dynamics of the Capitalist Economy (1933-1970), Cambridge, UK: Cambridge University Press.

Keynes, J.M. (1936), General Theory of Employment, Interest and Money, London: Macmillan. Marx, K. (1885), Das Capital, Volume II: The Process of Circulation of Capital, Moscow: Progress Publishers.

Pasinetti, L.L. (1974a), 'Rate of profit and income distribution in relation to the rate of economic growth,' in L.L. Pasinetti, Growth and Income Distribution: Essays in Economic Theory, Cambridge, UK: Cambridge University Press, pp. 103-116.

Pasinetti, L.L. (1974b), 'The rate of profit in an expanding economy,' in L.L. Pasinetti, Growth and Income Distribution: Essays in Economic Theory, Cambridge, UK: Cambridge University Press, pp. 139-143.

Pasinetti, L.L. (1981), Structural Change and Economic Growth: A Theoretical Essay on the Dynamics of the Wealth of Nations, Cambridge, UK: Cambridge University Press. 